\title{
Early gastrostomy reduces the rate of ventilator-associated pneumonia in stroke or head injury patients
}

\author{
E. Kostadima*, A.G. Kaditis\#, E.I. Alexopoulos\#, E. Zakynthinos* and D. Sfyras*
}

ABSTRACT: Presence of a nasogastric tube is a risk factor for the development of ventilatorassociated pneumonia (VAP). Alternatively, gastrostomy can be used for administration of enteral feedings.

To determine whether early performance of gastrostomy affects frequency of VAP, a randomised, controlled study was carried out in patients mechanically ventilated for stroke or head injury. In the gastrostomy group, patients underwent the procedure within $24 \mathrm{~h}$ of intubation. A nasogastric tube was inserted in controls. Individual subjects were studied for 3 weeks.

In total, 20 subjects (mean age $48 \pm 15.2$ yrs) were allocated to the gastrostomy group, and 21 to the control group (46.6 \pm 15.4 yrs). Of these groups, two $(10 \%)$ and eight $(38.1 \%)$ developed VAP, respectively. Four patients with gastrostomy and three controls did not complete the study (due to weaning from ventilatory support or death). After excluding these subjects, difference in VAP frequency persisted: two out of 16 subjects with gastrostomy had VAP (12.5\%) versus eight out of 18 controls (44.4\%). There were no differences in duration of hospitalisation or mortality between the two groups.

In conclusion, in patients mechanically ventilated for stroke or head injury early gastrostomy is associated with a lower frequency of ventilator-associated pneumonia compared with a nasogastric tube.

\section{KEYWORDS: Mechanical ventilation, nosocomial pneumonia}

$\mathbf{V}$ entilator-associated pneumonia (VAP) remains a common problem in the intensive care unit (ICU) despite early diagnosis and appropriate treatment [1]. Several studies have demonstrated that the cumulative risk for developing VAP increases with the duration of mechanical ventilation (MV). The rate of acquisition of VAP peaks around the fifth day of MV and plateaus at days 15 of respiratory support [2-5]. Early management of risk factors that have been implicated in the development of VAP could potentially decrease its incidence.

Some of the reported risk factors (e.g. patient's age, diagnosis on hospital admission and severity of illness) cannot be changed. However, variables such as duration of MV, use of paralytic agents, performance of tracheostomy and type of enteral nutrition can be potentially modified [6]. In most patients receiving $\mathrm{MV}$, a nasogastric tube is placed for evacuation of gastric secretions and for nutritional support. The presence of a nasogastric tube has been identified as an independent risk factor for $\operatorname{VAP}[7,8]$. The potential advantage of performing an early gastrostomy over using a nasogastric tube is the possibility of avoiding dysfunction of the upper and lower oesophageal sphincters and development of maxillary sinusitis, both of which are associated with VAP $[9,10]$.

The aim of the present preliminary investigation was to determine whether early performance of gastrostomy affects the frequency of VAP, compared with insertion of a nasogastric tube. It was hypothesised that administration of enteral feedings via a percutaneous gastrostomy, which was performed within $24 \mathrm{~h}$ after intubation in patients with stroke or head injury, is associated with a lower frequency of VAP compared with nutrition given via a nasogastric tube.

\section{PATIENTS AND METHODS \\ Subjects}

The protocol was reviewed and approved by the Larissa University Hospital Ethics Committee, Larissa, Greece. Over a 9-month period, intubated patients were recruited who were admitted

\section{AFFILIATIONS}

${ }^{*}$ Dept of Critical Care Medicine, and \#Dept of Pediatrics (Pediatric Pulmonology Unit), University of Thessaly School of Medicine and Larissa University Hospital, Larissa, Greece.

CORRESPONDENCE

E. Kostadima

Larissa University Hospital

Dept of Critical Care Medicine

P.O. Box 1425

Larissa 41110

Greece

Fax: 302410670838

E-mail: elenikostadima@yahoo.gr

Received:

August 172004

Accepted after revision:

March 142005

European Respiratory Journal

Print ISSN 0903-1936

Online ISSN 1399-3003 
directly to the ICU from the Emergency Department and who fulfilled certain inclusion criteria. After informed consent was obtained from a first degree relative, patients were randomly allocated to one of two treatment groups. In the early gastrostomy group, subjects underwent percutaneous gastrostomy within $24 \mathrm{~h}$ of intubation. In the control group, a nasogastric tube was inserted within the same time period.

Entry criteria were the following: 1) diagnosis of stroke or head injury; 2) Glasgow Coma Score of $<6$; and 3) need for sedation and MV. Participants in the study were monitored for 3 weeks following admission to the ICU or until development of VAP (which ever came first). Since the rate of acquisition of VAP peaks around the fifth day of MV and plateaus at day 15 of respiratory support [2-5], subjects were followed for 3 weeks to ensure that the majority of episodes of VAP would be included in the data analysis. If patients were still mechanically ventilated beyond the third week of their stay in the ICU, gastric feedings were continued. A gastrostomy was performed at 3 weeks for those who were previously in the control group (feedings via a nasogastric tube).

Exclusion criteria were: 1) history of known respiratory disease; 2) thoracic trauma; and 3) multiple traumatic injuries. Patients with contraindications for performance of gastrostomy or early initiation of enteral nutrition were not considered for study participation. Pre-existing respiratory disease is an independent predictor of VAP [5]. Similarly, thoracic trauma is frequently complicated by VAP [11]. Furthermore, thoracic tissue injury and the associated radiographic abnormalities may possibly decrease the usefulness of chest radiographs in diagnosing VAP. Multiple injuries often include abdominal or spinal trauma. Abdominal trauma is a contraindication for gastrostomy and administration of enteral feedings, while spinal trauma may require use of systemic corticosteroids, which is a risk factor for VAP [12].

\section{Treatment protocol and data collection}

Percutaneous gastrostomy was performed at the bedside by two of the ICU attending physicians, using the Flexiflo InvertaPEG Pull gastrostomy kit with roll-tip bumper (Abbott, Sligo, Ireland) within $24 \mathrm{~h}$ of intubation. All participants received continuous gastric feedings at a rate of $60-80 \mathrm{~mL} \cdot \mathrm{h}^{-1}$. Nutrition was initiated $24 \mathrm{~h}$ after performance of gastrostomy for the early gastrostomy group and within $48 \mathrm{~h}$ after intubation for the control group.

Patients were orally intubated [13], placed on the ICU bed in a semi-recumbent position (30-45) [14] and tracheostomy was not performed until completion of 3 weeks of MV. No closed circuits for tracheal suctioning were used [15]. Patients were sedated with midazolam and/or propofol and no muscle relaxants were required. Intracranial pressure was monitored in all subjects by an intracranial catheter and for this reason ceftriaxone was administered intravenously at a dose of $2 \mathrm{~g}$ every $12 \mathrm{~h}$. Ranitidine was also given intravenously at a dose of $50 \mathrm{mg}$ every $8 \mathrm{~h}$. None of the patients received any systemic corticosteroids during participation in the study [12].

The medical chart of each subject was reviewed and the following information was recorded: age, sex, admission diagnosis, Acute Physiology and Chronic Health Evaluation (APACHE) II score on admission [16], transports out of the ICU
[17], duration of MV and duration of stay in the ICU. Although in some studies APACHE II score has been associated with prognosis of head injury patients [1, 2], it is not the best predictor of disease severity. For this reason, similar disease severity between the study groups was ensured not only by comparing APACHE II scores, but also by using a Glasgow Coma Score of $<6$ as an entry criterion. A diagnosis of sinusitis by computed tomography scan was also noted [13]. If there was a suspicion of pneumonia during participation in the study, flexible bronchoscopy and bronchoalveolar lavage (BAL) were performed and BAL samples were sent for quantitative cultures.

For the diagnosis of VAP the criteria proposed in the American Thoracic Society consensus statement were applied [18]. VAP was diagnosed if a new and persistent infiltrate developed on the chest radiograph and at least two of the following criteria were fulfilled: 1) fever, an increase of $>1{ }^{\circ} \mathrm{C}$ or core temperature $>38.3^{\circ} \mathrm{C} ; 2$ ) leukocytosis, $25 \%$ increase in leukocyte count from baseline and an absolute count $>10,000 \cdot \mathrm{mm}^{-3}$ or leukopenia, $25 \%$ decrease in leukocyte count from baseline and an absolute count $<5,000 \cdot \mathrm{mm}^{-3}$; and 3) purulent tracheal aspirates, $>25$ neutrophils per high-power field on Gram stain. The diagnosis of VAP was augmented by a positive culture of BAL fluid $\left(\geqslant 10^{4}\right.$ colony forming units $\left.(\mathrm{cfu}) \cdot \mathrm{mL}^{-1}\right)$. However, a positive BAL fluid culture was not required for the diagnosis of VAP.

\section{Statistics and data analysis}

The two study groups were compared regarding: age, sex, diagnosis on admission, APACHE II score, per cent of subjects with at least one transport out of the ICU and per cent of subjects with acute sinusitis or history of cardiovascular disease. For continuous characteristics, an unpaired t-test was used, while for categorical variables the Chi-squared test with Yate's correction was applied.

Frequency of VAP was the primary outcome measure. The groups were compared for VAP frequency by the Chi-squared test with Yate's correction. Statistical analysis regarding VAP frequency was first carried out on an intent-to-treat basis. The analysis was then repeated after excluding patients who did not complete the study. The current authors estimated that 45 patients per group had to be recruited in order to provide $80 \%$ power, with an alpha error of 0.05 for detecting a difference of $30 \%$ in the frequency of VAP between the two groups. Cumulative analysis of the frequency of VAP per group and for each week of the study was also performed. The two groups were compared regarding frequencies of VAP by the Chi-squared test with Yate's correction.

Length of stay in the ICU, duration of MV, ICU mortality, and mortality directly attributed to VAP were secondary outcome measures. To evaluate subjects for the previous variables, they were monitored beyond the 3-week study period, i.e. until discharge from the ICU or death. Comparisons for secondary outcome measures were carried out using an unpaired t-test (continuous characteristics) or the Chi-squared test (categorical variables).

\section{RESULTS}

\section{Patients' characteristics}

In total, 20 patients were randomly allocated to the early gastrostomy group and 21 subjects to the control group. 
Subjects' characteristics that may affect development of VAP are summarised in table 1 . No statistically significant differences regarding these characteristics were found between the two study groups. Pneumoperitoneum in one patient was the only complication after performance of gastrostomy and it resolved without any further consequences. None of the participants had clinically significant gastro-oesophageal reflux during enteral feeding or required administration of any prokinetic agents.

Four patients in the gastrostomy group did not complete the entire 3-week period of the intervention, two subjects were extubated on the 18th and 19th days of hospitalisation, respectively, and two more subjects expired due to brain death on the 9th and 12th days after admission, respectively. Three subjects in the control group did not remain in the study for the 3 weeks, one subject was extubated on the 13th day of hospitalisation and two more patients expired due to brain death or pulmonary embolism on the 5th and 16th hospitalisation days, respectively. Therefore, 16 subjects in the early gastrostomy group and 18 subjects in the control group completed the trial.

\section{Frequency of VAP and secondary outcome measures}

Two patients in the gastrostomy group fulfilled the radiological and clinical or laboratory criteria for diagnosis of VAP on the 5th and 7th days after admission. In both cases, Acinetobacter baumannii $\left(<10^{4} \mathrm{cfu} \cdot \mathrm{mL}^{-1}\right)$ was isolated from culture of the BAL sample. Eight subjects in the control group were diagnosed with VAP between the 6th and 12th days of hospitalisation, A. baumannii (three cases), Pseudomonas aeruginosa (2 cases) and Staphlococcus aureus (three cases) were isolated from culture of the BAL sample. In two out of the three

\begin{tabular}{|c|c|c|c|c|}
\hline \multirow{2}{*}{$\begin{array}{l}\text { TABLE } 1 \\
\text { Variables }\end{array}$} & \multicolumn{4}{|c|}{$\begin{array}{l}\text { Summary statistics and statistical comparisons } \\
\text { between the early gastrostomy group and the } \\
\text { control group regarding variables that may affect } \\
\text { development of ventilator-associated pneumonia }\end{array}$} \\
\hline & & $\begin{array}{l}\text { Early gastrostomy } \\
\text { group }\end{array}$ & $\begin{array}{l}\text { Control } \\
\text { group }\end{array}$ & p-value \\
\hline \multicolumn{2}{|l|}{ Subjects $n$} & 20 & 21 & \\
\hline \multicolumn{2}{|l|}{ Age yrs } & $48 \pm 15.2$ & $46.6 \pm 15.4$ & $>0.05$ \\
\hline \multicolumn{2}{|l|}{ Females } & $4(20)$ & $5(24)$ & $>0.05$ \\
\hline \multicolumn{5}{|c|}{ Diagnosis on admission } \\
\hline \multicolumn{2}{|l|}{ Stroke } & $13(65)$ & $12(57)$ & $>0.05$ \\
\hline \multicolumn{2}{|l|}{ Head injury } & $7(35)$ & $9(43)$ & \\
\hline \multicolumn{2}{|c|}{ APACHE II score } & $15 \pm 1.7$ & $14.7 \pm 1.4$ & $>0.05$ \\
\hline \multicolumn{5}{|c|}{ Transport out of the ICU } \\
\hline \multicolumn{2}{|c|}{ Yes } & $20(100)$ & $21(100)$ & $>0.05$ \\
\hline \multicolumn{5}{|c|}{ Paranasal sinusitis } \\
\hline \multicolumn{2}{|l|}{ Yes } & $9(45)$ & $10(48)$ & $>0.05$ \\
\hline \multicolumn{5}{|c|}{ Cardiovascular disease } \\
\hline \multicolumn{2}{|c|}{ Hypertension } & $8(40)$ & $7(33)$ & $>0.05$ \\
\hline \multicolumn{2}{|c|}{$\begin{array}{l}\text { Diastolic dysfunction of } \\
\text { left ventricle }\end{array}$} & $2(10)$ & $3(14)$ & $>0.05$ \\
\hline
\end{tabular}

Data are presented as mean \pm SD or $n(\%)$. APACHE: Acute physiology and chronic health evaluation; ICU: Intensive care unit. cases with growth of $S$. aureus in the BAL sample, the isolated microorganism was found in a concentration $<10^{4} \mathrm{cfu} \cdot \mathrm{mL}^{-1}$.

When the two groups were compared on an intent-to-treat basis, subjects with gastrostomy had a lower frequency of VAP than controls. VAP occurred in two out of 20 patients $(10 \%)$ in the gastrostomy group versus eight out of 21 patients $(38.1 \%)$ in the control group $(\mathrm{p}=0.036)$. After excluding subjects who did not complete the study, the difference in VAP frequency between the two groups was still significant. Two out of 16 subjects with gastrostomy $(12.5 \%)$ developed VAP versus eight out of 18 controls $(44.4 \% ; \mathrm{p}=0.041)$. The results of cumulative analysis of the frequency of VAP per group and for each week of the study are presented in table 2.

There were no differences between the two study groups regarding secondary outcome measures (table 3). No subjects developed VAP after the end of the 3-week study period. However, six more deaths occurred. Two subjects expired in the gastrostomy group. One patient died due to acute lung

\begin{tabular}{|c|c|c|c|c|}
\hline \multirow[t]{3}{*}{ TABLE 2} & \multicolumn{4}{|c|}{$\begin{array}{l}\text { Cumulative analysis of frequency of ventilator- } \\
\text { associated pneumonia (VAP) per group and for } \\
\text { each week of the study }\end{array}$} \\
\hline & \multirow{2}{*}{$\begin{array}{c}\text { Subjects } \\
n\end{array}$} & \multicolumn{3}{|c|}{ Patients with VAP } \\
\hline & & $\begin{array}{c}\text { End of } \\
\text { 1st week }\end{array}$ & $\begin{array}{l}\text { End of } \\
\text { 2nd week }\end{array}$ & $\begin{array}{c}\text { End of } \\
\text { 3rd week }\end{array}$ \\
\hline $\begin{array}{l}\text { Early gastrostomy } \\
\text { group }\end{array}$ & 20 & $2 / 20^{\#}(10)$ & $2 / 18^{\#}(11.1)$ & $2 / 16^{\#}(12.5)$ \\
\hline Control group & 21 & $1 / 20^{\#}(5)$ & $8 / 19^{\#}(42.1)$ & $8 / 18^{\#}(44.4)$ \\
\hline p-value & & $>0.05$ & $<0.05$ & $<0.05$ \\
\hline
\end{tabular}

Data are presented as $\mathrm{n}(\%)$. ${ }^{*}$ : The denominator indicates the number of participants remaining in the study at the end of each week.

TABLE 3 Summary statistics and statistical comparisons between the early gastrostomy group and the control group regarding secondary outcome measures

\begin{tabular}{lccc}
$\begin{array}{l}\text { Secondary outcome } \\
\text { measures }\end{array}$ & $\begin{array}{c}\text { Early gastrostomy } \\
\text { group }\end{array}$ & $\begin{array}{c}\text { Control } \\
\text { group }\end{array}$ & p-value \\
\hline $\begin{array}{l}\text { Subject } \mathbf{n} \\
\text { Length of stay in ICU days }\end{array}$ & $38.5 \pm 14.2$ & $38.5 \pm 13.4$ & $>0.05$ \\
$\begin{array}{l}\text { Duration of mechanical } \\
\text { ventilation days }\end{array}$ & $37.3 \pm 13.7$ & $37.6 \pm 12.8$ & $>0.05$ \\
$\begin{array}{l}\text { ICU mortality no. deaths } \\
\text { ICU mortality attributed to }\end{array}$ & $4(20)^{\#}$ & $6(28.5)^{\boldsymbol{n}}$ & $>0.05$ \\
$\quad 1(5)$ & $1(4.7)$ & $>0.05$ \\
$\quad$ VAP no. deaths & & & \\
\hline
\end{tabular}

Data are presented as mean \pm SD or $n(\%)$. ICU: Intensive care unit; VAP ventilator-associated pneumonia. \#: causes of death: brain death (2), heart failure (1), VAP-associated acute lung injury (1); $\because$ : causes of death: brain death (1), heart failure (1), pulmonary embolism (1), VAP (1), mesenteric artery embolism (1), disseminated candidiasis (1) 
injury associated with VAP, which was diagnosed during the study period. Four patients expired in the control group. Only one death was related to VAP diagnosed during the study period. When all subjects were followed until weaning from ventilatory support and discharge from the ICU or until death, the overall ICU mortality and the mortality attributed to VAP were similar among the two study groups (table 3 ).

\section{DISCUSSION}

Presence of a nasogastric tube has been recognised as one of the risk factors for the development of $\operatorname{VAP}[7,8]$. It is possible that use of an alternative method to provide enteral feedings could decrease the frequency of VAP. In the present controlled study, the frequency of VAP in subjects who receive enteral feedings via a gastrostomy tube and in those fed via a nasogastric tube was compared. All participants had a poor Glasgow Coma Score due to head injury or stroke. Patients in the early gastrostomy group were found to have a significantly lower frequency of VAP compared with subjects in the control group (nasogastric tube).

To the current authors' knowledge, this is the first controlled study assessing the possible decrease in the risk for developing VAP after performance of early gastrostomy in comparison with use of a nasogastric tube. In an older retrospective report of subjects operated on for abdominal aortic aneurysm, the frequency of "chest" infections was lower in those who underwent performance of gastrostomy intra-operatively than in patients with a nasogastric tube [19].

Provision of adequate nutritional support for critically ill patients is one of the main goals of the ICU medical care team [20]. Early administration of enteral feedings is considered to be of benefit to MV subjects. Despite this concept, a prospective trial showed that subjects with respiratory failure who were scheduled to receive their estimated total daily nutrition requirement on day one of $\mathrm{MV}$ had a statistically greater occurrence of VAP than those who were scheduled to receive full enteral nutrition on day five [21]. Most subjects received bolus gastric feedings via a nasogastric or orogastric tube. The authors of that study suggested that suboptimal infusion of enteral nutrition results in more harm than no infusion at all and that further investigations are required to identify the best method of providing feedings to patients with acute respiratory failure.

A number of mechanisms have been proposed to explain why the presence of a nasogastric tube is associated with an increased risk for development of pneumonia. These mechanisms include: 1) disturbance of the physiological pharyngoglottal reflexes that prevent aspiration [22]; 2) dysfunction of the upper and lower oesophageal sphincters and associated gastro-oesophageal reflux secondary to the presence of the tube [9]; and 3) colonisation of the stomach by bacteria that may subsequently migrate to the oropharynx and into the lower respiratory tract (gastropulmonary hypothesis) [23, 24].

Use of a nasogastric tube is not practical as a long-term solution for providing enteral feedings. In a retrospective anecdotal review of the authors experience in the Larissa University Hospital ICU, they found that $>60 \%$ of patients with stroke or head injury and poor Glasgow Coma Score required performance of gastrostomy prior to their hospital discharge. These subjects usually had a decreased level of consciousness and/or dysfunctional swallowing on discharge. Since percutaneous gastrostomy was inevitable for the majority of patients with the previous characteristics, the current authors decided to perform the procedure soon after intubation.

The present authors hypothesised that administration of enteral feedings via a percutaneous gastrostomy, performed within $24 \mathrm{~h}$ after intubation, may be related to a lower frequency of VAP compared with nutrition given via a nasogastric tube. Early performance of gastrostomy could possibly prevent disturbance of the physiological pharyngoglottal reflexes (which leads to aspiration) and dysfunction of the upper and lower oesophageal sphincters due to the presence of a nasogastric tube.

Use of an early gastrostomy instead of a nasogastric tube could also decrease the incidence of paranasal sinusitis. The incidence of infectious maxillary sinusitis and its relationship to VAP were prospectively studied in critically ill patients who were mechanically ventilated for a period $>7$ days [10]. Infectious maxillary sinusitis was significantly associated with VAP and its frequency was markedly reduced by inserting endotracheal and gastric tubes via the oral route and not via the nares.

In the present study, both study groups were similar regarding characteristics that may have affected VAP frequency (age, diagnosis on admission, APACHE II score, history of transports out of the ICU, diagnosis of paranasal sinusitis and history of cardiovascular disease) $[5,7]$. A standard treatment protocol was used to ensure that no known confounding factors would influence the difference in frequency of VAP between the two study groups. Specifically, all participants were orally intubated [13], placed in a $30-45^{\circ}$ semi-recumbent position [14] and received the same antibiotic and $\mathrm{H} 2$ receptor antagonists treatment regimen $[25,26]$.

More patients with nasogastric tube developed VAP compared with subjects with gastrostomy. VAP has been defined as earlyonset if occurring within the first 3-7 days after intubation [4, 26-28]. Haemophilus influenzae, Streptococcus pneumoniae, methicillin-sensitive $S$. aureus and susceptible gram-negative bacteria have been mostly associated with early-onset VAP, while $P$. aeruginosa, Acinetobacter spp., methicillin-resistant $S$. aureus and multiresistant gram-negative bacteria have been mainly related to late-onset pneumonia [28, 29]. In this report, all cases of pulmonary infections, except one, occurred after the 5 th day of ventilatory support and the isolated microorganisms were among those frequently found in late-onset VAP. Although VAP occurred in fewer patients with gastrostomies, there were no differences in secondary outcome measures between the two groups. Two out of ten subjects with VAP expired secondary to the pulmonary infection after completion of the 3-week study (case fatality rate of $20 \%$ ), which is consistent with findings in other reports [30].

Several complications have been related to percutaneous gastrostomy, such as peritonitis, gastric perforation, wound infection, pneumoperitoneum and tube blockage [31, 32]. In this series, the only complication secondary to gastrostomy was pneumoperitoneum in one case, which subsequently resolved without any other consequences. 
The main limitation of the current study was the small number of participants; for this reason further controlled studies with larger numbers of subjects are necessary to confirm the authors findings. At the time of designing this trial, there was controversy in the literature over appropriate timing of tracheostomy. Since tracheostomy is a possible covariate in the association between enteral feedings and VAP, the procedure was not performed until the end of the 3 weeks of the study. Nevertheless, recent evidence suggests that early tracheostomy may have significant benefits over late tracheostomy, including reduction in mortality rate, frequency of pneumonia, duration of MV and length of stay in the ICU [33].

In conclusion, the results of this preliminary investigation indicate that administration of enteral feedings via a percutaneous gastrostomy, which is performed early after intubation in subjects mechanically ventilated for stroke or head injury, is associated with a lower frequency of ventilator-associated pneumonia compared with nutrition via a nasogastric tube. Further controlled studies with larger number of subjects are necessary to confirm that early performance of gastrostomy is an effective measure for reducing the incidence of ventilatorassociated pneumonia.

\section{REFERENCES}

1 Chastre J, Fagon JY. Ventilator-associated pneumonia. Am J Respir Crit Care Med 2002; 165: 867-903.

2 Langer M, Mosconi P, Cigada M, Mandelli M. Long-term respiratory support and risk of pneumonia in critically ill patients. Intensive care unit group of infection control. Am Rev Respir Dis 1989; 140: 302-305.

3 Fagon JY, Chastre J, Domart Y, et al. Nosocomial pneumonia in patients receiving continuous mechanical ventilation. Prospective analysis of 52 episodes with use of a protected specimen brush and quantitative culture techniques. Am Rev Respir Dis 1989; 139: 877-884.

4 Langer M, Cigada M, Mandelli M, Mosconi P, Tognoni G. Early onset pneumonia: a multicenter study in intensive care units. Intensive Care Med 1987; 13: 342-346.

5 Cook DJ, Walter SD, Cook RJ, et al. Incidence of and risk factors for ventilator-associated pneumonia in critically ill patients. Ann Intern Med 1998; 129: 433-440.

6 Cook D. Ventilator associated pneumonia: perspectives on the burden of illness. Intensive Care Med 2000; 26, Suppl. 1: S31-S37.

7 Joshi N, Localio AR, Hamory BH. A predictive risk index for nosocomial pneumonia in the intensive care unit. Am J Med 1992; 93: 135-142.

8 Leal-Noval SR, Marquez-Vacaro JA, Garcia-Curiel A, et al. Nosocomial pneumonia in patients undergoing heart surgery. Crit Care Med 2000; 28: 935-940.

9 Kuo B, Castell DO. The effect of nasogastric intubation on gastroesophageal reflux: a comparison of different tube sizes. Am J Gastroenterol 1995; 90: 1804-1807.

10 Rouby JJ, Laurent $\mathrm{P}$, Gosnach M, et al. Risk factors and clinical relevance of nosocomial maxillary sinusitis in the critically ill. Am J Respir Crit Care Med 1994; 150: 776-783.

11 Segers P, Van Schil P, Jorens P, Van Den Brande F. Thoracic trauma: an analysis of 187 patients. Acta Chir Belg 2001; 101: 277-282.
12 Pawar M, Mehta Y, Khurana P, Chaudhary A, Kulkarni V, Trehan N. Ventilator-associated pneumonia: Incidence, risk factors, outcome, and microbiology. J Cardiothorac Vasc Anesth 2003; 17: 22-28.

13 Holzapfel L, Chastang C, Demingeon G, Bohe J, Piralla B, Coupry A. A randomized study assessing the systematic search for maxillary sinusitis in nasotracheally mechanically ventilated patients. Influence of nosocomial maxillary sinusitis on the occurrence of ventilatorassociated pneumonia. Am J Respir Crit Care Med 1999; 159: 695-701.

14 Drakulovic MB, Torres A, Bauer TT, Nicolas JM, Nogue S, Ferrer M. Supine body position as a risk factor for nosocomial pneumonia in mechanically ventilated patients: a randomised trial. Lancet 1999; 354: 1851-1858.

15 Combes P, Fauvage B, Oleyer C. Nosocomial pneumonia in mechanically ventilated patients, a prospective randomised evaluation of the Stericath closed suctioning system. Intensive Care Med 2000; 26: 878-882.

16 Knaus WA, Draper EA, Wagner DP, Zimmerman JE. APACHE II: a severity of disease classification system. Crit Care Med 1985; 13: 818-829.

17 Kollef MH, Von Harz B, Prentice D, et al. Patient transport from intensive care increases the risk of developing ventilator-associated pneumonia. Chest 1997; 112: 765-773.

18 American Thoracic Society. Hospital-acquired pneumonia in adults: diagnosis, assessment of severity, initial antimicrobial therapy, and preventive strategies. Am J Respir Crit Care Med 1996; 153: 1711-1725.

19 Morris T, Bouhoutsos J, Martin P. The value of gastrostomy in the surgery of aortic aneurysms. Br J Surg 1974; 61: 662-664.

20 Wilmore DW. Catabolic illness. Strategies for enhancing recovery. N Engl J Med 1991; 325: 695-702.

21 Ibrahim EH, Mehringer L, Prentice D, et al. Early versus late enteral feeding of mechanically ventilated patients: results of a clinical trial. J Parenter Enteral Nutr 2002; 26: 174-181.

22 DeMeo MT, Bruninga K. Physiology of the aerodigestive system and aberrations in that system resulting in aspiration. J Parenter Enteral Nutr 2002; 26: Suppl. 6, S9-S17.

23 Driks MR, Craven DE, Celli BR, et al. Nosocomial pneumonia in intubated patients given sucralfate as compared with antacids or histamine type 2 blockers. The role of gastric colonization. N Engl J Med 1987; 317: 1376-1382.

24 Tryba M. The gastropulmonary route of infection-fact or fiction? Am J Med 1991; 91, Suppl. 2A: 135S-146S.

25 D'Amico R, Pifferi S, Leonetti C, Torri V, Tinazzi A, Liberati A. Effectiveness of antibiotic prophylaxis in critically ill adult patients: systematic review of randomised controlled trials. BMJ 1998; 316: 1275-1285.

26 Prod'hom G, Leuenberger P, Koerfer J, et al. Nosocomial pneumonia in mechanically ventilated patients receiving antacid, ranitidine, or sucralfate as prophylaxis for stress ulcer. A randomized controlled trial. Ann Intern Med 1994; 120: 653-662.

27 Baker AM, Meredith JW, Haponik EF. Pneumonia in intubated trauma patients. Microbiology and outcomes. Am J Respir Crit Care Med 1996; 153: 343-349. 
28 Trouillet JL, Chastre J, Vuagnat A, et al. Ventilatorassociated pneumonia caused by potentially drugresistant bacteria. Am J Respir Crit Care Med 1998; 157: 531-539.

29 Rello J, Sa-Borges M, Correa H, Leal SR, Baraibar J. Variations in etiology of ventilator-associated pneumonia across four treatment sites: implications for antimicrobial prescribing practices. Am J Respir Crit Care Med 1999; 160: 608-613.

30 Hubmayr RD, Burchardi $\mathrm{H}$, Elliot M, et al. Statement of the 4th International Consensus Conference in Critical Care on ICU-Acquired Pneumonia-Chicago, Illinois, May 2002. Intensive Care Med 2002; 28: 1521-1536.
31 Hull MA, Rawlings J, Murray FE, et al. Audit of outcome of long-term enteral nutrition by percutaneous endoscopic gastrostomy. Lancet 1993; 341: 869-872.

32 Loser C, Wolters S, Folsch UR. Enteral long-term nutrition via percutaneous endoscopic gastrostomy (PEG) in 210 patients: a four-year prospective study. Dig Dis Sci 1998; 43: 2549-2557.

33 Rumbak MJ, Newton M, Truncale T, Schwartz SW, Adams JW, Hazard PB. A prospective, randomized, study comparing early percutaneous dilational tracheotomy to prolonged translaryngeal intubation (delayed tracheotomy) in critically ill medical patients. Crit Care Med 2004; 32: 1689-1694. 